\title{
Medical Information on the Internet
}

\author{
A Study of an Electronic Bulletin Board \\ Jean Deason Culver, MD, MPH, Fredric Gerr, MD, Howard Frumkin, MD, DrPH
}

\begin{abstract}
OBJECTIVE: To assess medical information provided in a medically oriented Internet discussion group, in terms of the professional status of the individuals providing information, the consistency of the information with standard medical practice, and the nature of the evidence cited in support of specific claims or recommendations.
\end{abstract}

DESIGN: Standardized review of 1,658 consecutive messages on a particular online discussion group during a 5-month period.

SETTING: An online discussion group for sufferers of painful hand and arm conditions.

SUBJECTS: All participants in this discussion group during the study period.

MEASUREMENTS AND MAIN RESULTS: Professional training of those offering medical information, consistency of the advice and recommendations offered with conventional medical practice, and nature of evidence cited in support of medical claims were determined. Of all messages, 55.9\% (927) addressed a medical topic. Of these, $79 \%$ (732) provided medical information, of which $89.3 \%$ (654) were authored by persons without professional medical training, and $5.1 \%$ (37) were authored by trained health professionals. Approximately one third of the medical information provided was classified as unconventional. Personal experience was the basis of information provided in $61 \%$ of the nonprofessionals' messages and $13.5 \%$ of the professionals' messages, while no source was given as the basis of information provided in $29.8 \%$ of the nonprofessionals' messages and $67.6 \%$ of the professionals' messages. A published source was cited in $9.2 \%$ of the nonprofessionals' and $\mathbf{1 8 . 9 \%}$ of the professionals' messages.

CONCLUSIONS: These findings suggest that medical information available on Internet discussion groups may come from nonprofessionals and may be unconventional, based on limited evidence, and/or inappropriate.

KEY WORDS: medical information; Internet; computer communication networks; quality assurance; alternative medicine; self-help groups.

J GEN INTERN MED 1997;12:466-470.

Received from the Department of Environmental and Occupational Health, Rollins School of Public Health of Emory University, Atlanta, Ga.

Dr. Culver was supported, in part, by Occupational Safety and Health Training Grant TO1/CCT410462, from the National Institute for Occupational Safety and Health. Dr. Frumkin was supported, in part, by Environmental/Occupational Medicine Academic Award KO7 ESO0257 from the National Institute of Environmental Health Sciences.

Address correspondence and reprint requests to Dr. Frumkin: Department of Environmental and Occupational Health, Rollins School of Public Health of Emory University, 1518 Clifton Rd., Atlanta, GA 30322
$\boldsymbol{\Gamma}$ he Internet provides ready access to vast amounts of 1 medical information, heralding what one observer has called "the next transformation in the delivery of health care." 1 Physicians can access extensive medical databases such as Medline, CancerNet, and OncoLink; create, archive, and instantly access electronic medical records; and seek instantaneous long-distance consultations. ${ }^{2} \mathrm{~Pa}-$ tients, for their part, can also access medical information and participate in electronic discussion groups. Anyone can set up a Web site and offer medical information and opinion. ${ }^{3,4}$ Recent editorials, letters, and articles in the medical literature have addressed the explosion of medical information available on the Internet. ${ }^{4-11}$

The free flow of information is usually considered a social good; however, several concerns arise in connection with medical information on the Internet. One, which has been relatively well discussed, is the threat to patients' medical confidentiality, as the security of computer databases can be breached. ${ }^{12}$ Another, which has received less attention but has been mentioned in the popular press (Wall Street Journal. February 27, 1995:1 and New York Times. April 10, 1996:C1), is the possibility that misinformation may be widely disseminated..$^{7,13-15}$ Similarly, controversial information may be presented in a biased manner, without balance or even an acknowledgment of its limits. The basis or source of medical claims, if indeed there is any, may not be cited. Trained and qualified persons may offer medical advice, but so may anybody else. Information on the Internet may not be peer-reviewed. At a time of rapid proliferation of Internet sites and discussion groups (New York Times. October 28, 1996:C1), the opportunities for "cyber-snake-oil-salesmen," in the words of Massachusetts Attorney General Scott Harshbarger, ${ }^{14}$ and the potential for harm, are considerable.

This study was designed to address two hypotheses. First, we hypothesized that medical information on an Internet discussion group might be provided by nonmedical personnel, or by personnel with unidentified professional credentials. Second, we hypothesized that medical information on an Internet discussion group might be inconsistent with current accepted medical practice, not based on evidence, without benefit, and even harmful. To test these hypotheses we identified an Internet discussion group focused on a specific medical topic, and conducted a systematic review of all messages posted during a defined time interval.

\section{METHODS}

The online discussion group selected for study was SOREHAND, a bulletin board dedicated to discussion of painful hand and arm conditions occurring in association 
with repetitive or forceful use of the hands, sometimes called "repetitive strain injury" by those who experience them. ${ }^{16}$ SOREHAND can be accessed at SOREHAND@ ucsfvm.ucsf.edu.

All messages appearing on the bulletin board between February 14 and July 20, 1994 were characterized according to several criteria, including the qualifications of the author, the purpose of the message, the content of the message, the nature of any medical advice given (including the cost implications of compliance), and expression of medical dissatisfaction by the author. The subset of messages in which medical information was provided were classified further by source and type of medical information. Details of the classification scheme appear below.

The type of author was classified according to the following categories: affected person; health care provider; ergonomist or other safety or exposure control expert; vendor of hardware, software, ergonomic equipment, or furniture; other; or unknown. The health care provider entries were further subclassified as physician (medical doctor or doctor of osteopathy), nurse, chiropractor, physical or occupational therapist, or other. This variable was determined from self-identification by the author, inferred from message content, or recognized from previous messages on the bulletin board. Forwarded messages were classified according to the individual who had forwarded the message to the bulletin board, not the original author.

The purpose of message variable was coded according to whether the author was requesting information, providing information, both requesting and providing information, performing housekeeping functions of the bulletin board itself, or none of these (other).

On the basis of the content of message variable, messages were classified into one of three content areas: (1) software, hardware, furniture, and ergonomic topics; (2) medical topics; and (3) all other topics. A message that described a procedure or piece of equipment, but then made specific medical claims for it, was classified as a medical message.

We identified a subgroup comprising messages on medical topics whose purpose was to "provide information," and classified these according to three other variables: (1) the medical training of the author, (2) the "conventionality" of information provided, and (3) the source of information. The medical training of author variable indicated whether the message author had professional training in a health care field and, if so, what type of training. The conventionality of information variable indicated whether the information provided was consistent with generally accepted medical practice, based on either published, peer-reviewed scientific evidence or standard practice.

Examples of conventional diagnoses included carpal tunnel syndrome or tendinitis, and examples of conventional ergonomic interventions and medical treatments included furniture or workstation adjustments, decreases in exposure time to repetitive motions, physical and occupational therapy, treatment with nonsteroidal anti- inflammatory medication, immobilization, and surgery after a trial of conservative therapy. Examples of unconventional medical information included diagnoses such as "adverse mechanical tension" of the nervous system, and treatments such as therapeutic magnetism or aromatherapy. The source of information variable indicated whether the information provided was based on a published citation, generally a peer-reviewed scientific journal, or on personal experience, or on neither of these.

For each message that provided a specific medical recommendation, we estimated the cost of compliance, using three categories: none $(\leq \$ 10)$, such as a change of posture; low ( $>\$ 10$ to $\leq \mathbf{\$} 200$ ), such as obtaining a splint or visiting a doctor; or high $(>\$ 200)$, such as surgery. To the extent possible our cost estimates included indirect costs for either employer or patient, such as the economic impact of quitting a job. If the medical information did not recommend a specific intervention for which a cost could be estimated, this variable was coded as "not applicable."

A variable for surgical recommendation was coded as positive when a message included a recommendation for a surgical intervention. If a specific intervention was not recommended, this variable was coded as "not applicable." A variable indicating dissatisfaction with the medical system was coded as positive when the author expressed lack of treatment success or frustration with medical care.

The coding form was initially validated by duplicate coding of 100 messages. All messages were initially coded by a single reviewer (JDC); those that were ambiguous or difficult to code were independently assessed by all three authors, and a consensus opinion was used for the final coding of these messages. Repeated messages were counted as many times as they appeared.

\section{RESULTS}

A total of 1,658 messages appeared on SOREHAND during the study interval and were coded. Consensus coding was required for $0.4 \%$ (7) of the messages. The 1,658 messages originated from a total of 313 authors. Of the messages, $370(22.3 \%)$ came from four "high-volume" authors who sent more than 50 messages (mean 92.5) each. Another 213 messages (12.8\%) came from 14 "medium-volume" authors who sent between 20 and 49 (mean 23.5) messages each. The remaining 1,075 messages $(64.8 \%)$ came from 295 "occasional" authors who sent fewer than 20 (mean 3.6) messages each. The majority of authors sent messages only occasionally; of the total of 313 authors, 254 (81.1\%) sent 5 or fewer messages.

Most $(72 \%)$ of the messages were written by affected persons (Table 1). Health care providers, as a group, wrote $5.3 \%$ (88) of the messages. Only 5 of these 88 messages were written by a physician; the remainder were written by nurses, chiropractors, physical or occupational therapists, or others. In $10.1 \%$ (168) of the messages, the author's professional status could not be identified. 
Table 1. Type of Author

\begin{tabular}{lrr}
\hline \hline Author Identification & \% & \multicolumn{1}{c}{$\boldsymbol{n}$} \\
\hline Affected person & 72.0 & 1,194 \\
MD/DO & 0.3 & 5 \\
Nurse & 1.1 & 19 \\
Chiropractor & 0.1 & 2 \\
Physical/occupational therapist & 2.1 & 34 \\
Other health care provider & 1.7 & 28 \\
Ergonomist/safety expert & 7.4 & 122 \\
Vendor & 2.5 & 41 \\
Other & 2.7 & 45 \\
Unknown & 10.1 & 168 \\
Total & $\mathbf{1 0 0 . 0}$ & $\mathbf{1 , 6 5 8}$ \\
\hline
\end{tabular}

Information was provided in about two thirds of the messages and requested in about one fifth of the messages (Table 2). Housekeeping activities accounted for less than $10 \%$ of the messages.

Table 3 shows that $23.1 \%$ (383) of the messages focused exclusively on software, hardware, or ergonomic topics, while 55.9\% (927) were concerned with medical topics. Of the 927 messages with a medical topic, 732 provided (rather than requested) information. Of these, 89.3\% (654) came from persons without professional training, 5.1\% (37) came from health professionals, and $5.6 \%$ (41) came from persons whose professional background could not be identified. In providing information, the nonprofessionals based $61 \%$ of their messages on personal experience (Table 4), while the professionals based $13.5 \%$ of their messages on personal experience (Table 5). No basis for the recommendation was apparent in $29.8 \%$ of nonprofessionals' messages (Table 4) and 67.6\% of the professionals' messages (Table 5). Interestingly, approximately one third of the messages written both by authors with and by authors without professional training were classified as unconventional.

Of the 732 messages in which medical information was provided (regardless of the author's professional status), more than $80 \%$ included some type of recommendation for intervention or treatment. Only $1 \%$ of the messages, however, recommended surgery. The cost was categorized as "high" for only $2.7 \%$ of the recommendations (data not shown). Finally, of the 927 messages that included a medical topic, nearly $10 \%$ expressed frustration with or complaints about medical care their authors had received.

Table 2. Message Purpose

\begin{tabular}{lrr}
\hline \hline Message Purpose & \multicolumn{1}{c}{$\%$} & \multicolumn{1}{c}{$\boldsymbol{n}$} \\
\hline Information requested & 21.4 & 354 \\
Information provided & 67.6 & 1,120 \\
Information requested and provided & 3.1 & 51 \\
Housekeeping & 7.0 & 116 \\
Other & 1.0 & 17 \\
Total & $\mathbf{1 0 0 . 0}$ & $\mathbf{1 , 6 5 8}$ \\
\hline
\end{tabular}

Table 3. Message Content

\begin{tabular}{lrr}
\hline \hline Message Content & \% & $\boldsymbol{n}$ \\
\hline Software/hardware/ergonomics & 23.1 & 383 \\
Medical & 55.9 & 927 \\
Other & 21.0 & 348 \\
Total & $\mathbf{1 0 0 . 0}$ & $\mathbf{1 , 6 5 8}$ \\
\hline
\end{tabular}

\section{DISCUSSION}

During the study period SOREHAND was a lively discussion forum focused on a relatively specific set of medical problems, mostly among persons with upper extremity symptoms. Participants described their symptoms and sought advice, solace, and support. Many of the requests for information were credulous, uncritical, and even desperate. One contributor wrote, "If a shaman can relieve my pain without making me throw up, I'm willing to give his method a try."

In response, much information was offered, often in the form of personal advice. Most messages providing information on a medical topic were written by individuals without professional medical training, as predicted by our first hypothesis. In our sample, 5.3\% of the messages were written by health care providers and only $0.3 \%$ were written by physicians. The advice offered frequently had little basis in biomedical science or accepted medical practice. The source of the information in $60 \%$ of messages was personal experience alone. Slightly more than one third of messages recommended unconventional interventions for upper extremity pain, such as acupuncture, aromatherapy, Qi Gong, homeopathy, and Jin Shin Jytsu. These findings support our second hypothesis.

Typically, a new discussion group member described one or two symptoms and elicited numerous responses about the nature of the problem and how best to manage it. For example, one new arrival wrote, "I have what I think are the beginnings of carple's [sic] tunnel syndrome or maybe tendonitis in my left hand due to my computer habit/addiction." One respondent urged the use of special gloves, while another reviewed a textbook of myotherapy treatment methods. In this case, the diagnosis, treatment, and attribution to use of the computer appeared to be unverified. Similarly, another contributor wrote, "What I've developed is not at all in my wrists. I have sore elbows, and the muscles going down my arms become sore. I cannot lift heavy things and have begun backing off of computer time." One respondent wrote, "It's your basic tendinitis or myofascial pain. I had something very similar. It could be related to thoracic outlet syndrome."

In general, contributors appeared to assume that what was stated by other contributors was true, and there was a conspicuous absence of critical evaluation of conclusions drawn. For example, a contributor wrote, "I moved on the weekend and figured that I'd be next to useless with unpacking etc. . . . I shifted a lot of boxes, car- 
Table 4. Medical Information Provided by Individuals Without Professional Training

\begin{tabular}{|c|c|c|c|c|c|c|c|c|}
\hline \multirow[b]{2}{*}{ Type of Information } & \multicolumn{2}{|c|}{ No Source Given } & \multicolumn{2}{|c|}{$\begin{array}{l}\text { Published } \\
\text { Citation }\end{array}$} & \multicolumn{2}{|c|}{$\begin{array}{c}\text { Personal } \\
\text { Experience }\end{array}$} & \multicolumn{2}{|c|}{ Total } \\
\hline & $\%$ & $n$ & $\%$ & $n$ & $\%$ & $n$ & $\%$ & $n$ \\
\hline Conventional & 17.6 & 115 & 4.1 & 27 & 42.7 & 279 & 64.4 & 421 \\
\hline Unconventional & 12.2 & 80 & 5.0 & 33 & 18.3 & 120 & 35.6 & 233 \\
\hline Total & 29.8 & 195 & 9.2 & 60 & 61.0 & 399 & 100.0 & 654 \\
\hline
\end{tabular}

ried stuff from here to there, put up shelves (i.e., screwed in a lot of screws), and all without a twinge. As soon as I got back to work and started typing, I could feel things start to ache again. I guess it was a case of using different muscles, tendons, etc., and moving them in different ways." No one questioned these conclusions although other explanations could have been inferred from the stated facts.

Of the messages that contained medical information, almost $10 \%$ included complaints about medical care. Some expressed frustration: "The past year or so of doctor pinball has left me frustrated with what little medicine has to offer," and "I have found doctors to be pretty much useless. They cost a lot of money and they know less about the specifics of your body than a good physical therapist. Doctors simply do not spend enough time with their patients (they make too much money to treat us like individuals)." Some expressed anger: "The moral of the story is . . . see an Osteopath before you let the butchers cut you open!" or "I feel angry that this is a do it yourself area” or "MDs are not gods." Some expressed mistrust: "The reason they are running an EMG is because it is so painful that they hope you will give up your workman's comp claim." Messages from physicians may be rare in forums such as this one because they get the impression that their input is not welcomed.

Several methodologic problems limit the inferences that can be drawn from our results. First, we characterized medical advice as conventional or unconventional rather than assessing its efficacy or safety. These latter features are of greater interest, but were impossible to assess owing to the absence of rigorous data regarding most interventions for upper extremity symptoms.

Similarly, we could not evaluate the medical appropriateness of advice given, or assess risks and benefits of compliance. Most of the interventions recommended were low in cost and did not include surgery. In some cases more aggressive therapy may have had less risk, such as surgery after a trial of conservative treatment for carpal tunnel syndrome to prevent permanent nerve damage. The inability to assess the benefit or risk of recommendations is another limitation of the results of this study.

A related limitation was our inability to verify the identity and motives of authors, beyond the self-identification they provided. We did identify 41 messages $(2.5 \%$ of the total) as written by vendors interested in selling products; however, it is possible that other messages were written with concealed commercial intent, or to advance other agendas. There were so few messages written by persons with professional training that when stratified by source and type of information the categories were too small to provide meaningful information.

Our observations can be understood in at least two contexts: snake oil and self-help. Snake oil is a term applied to medical misinformation, and by extension to medical products with unproven efficacy or unproven safety. Although the term snake oil denotes willful deception, misinformation and unproven products may be dispensed for many reasons: honest error, a desire to promote a particular agenda or ideology, or a desire for commercial gain. Snake oil has a long history in health care, ${ }^{17-20}$ ranging from the promotion of questionable nutritional remedies, ${ }^{21}$ to unconventional therapies such as electromagnetic fields, ${ }^{22}$ and including treatments for arthritis, ${ }^{23}$ allergies, ${ }^{24}$ cancer, ${ }^{25}$ and AIDS. ${ }^{26}$ Snake oil may thrive in situations in which conventional medicine has little to offer, scientific data are equivocal, or patients are desperate, as the Laetrile episode demonstrated during the 1970 s and 1980 s. $^{27}$ In this context, the novelty of the Internet lies not so much in the potential for purveying snake oil, a long-standing phenomenon, but in the unprecedented rapidity, geographic reach, and low expense with which this may occur.

Internet discussion groups may also be understood within the tradition of self-help groups in health care. Selfhelp groups, a growing trend in the United States, ${ }^{28,29}$ vary greatly in style, subject, and format. Common characteris-

Table 5. Medical Information Given by Individuals with Professional Training

\begin{tabular}{|c|c|c|c|c|c|c|c|c|}
\hline \multirow[b]{2}{*}{ Type of Information } & \multicolumn{2}{|c|}{ No Source Given } & \multicolumn{2}{|c|}{$\begin{array}{l}\text { Published } \\
\text { Citation }\end{array}$} & \multicolumn{2}{|c|}{$\begin{array}{c}\text { Personal } \\
\text { Experience }\end{array}$} & \multicolumn{2}{|c|}{ Total } \\
\hline & $\%$ & $n$ & $\%$ & $n$ & $\%$ & $n$ & $\%$ & $n$ \\
\hline Unconventional & 24.3 & 9 & 5.4 & 2 & 2.7 & 1 & 32.4 & 12 \\
\hline Total & 67.6 & 25 & 18.9 & 7 & 13.5 & 5 & 100.0 & 37 \\
\hline
\end{tabular}


tics include a shared concern, self-governance, a democratic ideology, and nonprofit status. ${ }^{30}$ The Internet is well suited for self-help groups because it shares the characteristics of democracy and self-governance. Some bulletin boards have moderators who can block messages from a particular source if this is deemed necessary, but in general the "rules" are determined by those writing the messages.

The impact of self-help groups on their members is difficult to assess. Few studies have formally evaluated them, and contradictory results have emerged. ${ }^{27}$ Some anecdotal reports cite a positive effect, ${ }^{27}$ but these reports may suffer from various sources of positive bias. ${ }^{29}$ Positive effects of self-help groups may include useful information and emotional support, while negative effects may include misinformation and the reinforcement of disability. As one affected person wrote in a message we reviewed, SOREHAND "has been a great education for me, but I think it's turning me into a hypochondriac. Does [sic] anyone else's hands tingle as you read through the daily dose?" The efficacy of such groups, especially in the context of the Internet, remains to be evaluated.

Many of the participants reported symptoms that they attributed to using a computer keyboard, so it appeared incongruous that they turned for help to an activity that required more typing. This did not go unrecognized by one participant, who wrote, "From the start it has struck me as extremely ironic that all of us folks are sitting here (and there) doing what hurts us to talk about what hurts us."

A majority of the information on the forum we studied dealt with medically related subjects. Our observations corroborated previous concerns about accuracy, appropriateness, and sources of information on the Internet. Most of the advice was given by persons without professional training or credentials and was based on personal experience alone. Although the implied costs of the advice we reviewed were generally low, one third of the recommended interventions were unconventional. The advice provided was not individualized, and although the recommendations were generally not aggressive, compliance may in some cases have increased a patient's risk or caused harm.

The causes of upper extremity pain are diverse and incompletely understood. Conventional treatments vary in effectiveness, so it is not surprising that affected persons turn to an outlet such as the SOREHAND bulletin board for help. However, our observations support the concern that appropriate diagnosis and treatment may elude participants in such electronic bulletin board discussions, on a scale that is unprecedented.

\section{REFERENCES}

1. Kassirer JP. The next transformation in the delivery of health care. N Engl J Med. 1995;332:52-4.
2. Osheroff JA, Bankowitz RA. Physicians' use of computer software in answering clinical questions. Bull Med Libr Assoc. 1993;81:11-9.

3. Nagy K. Cancer information seekers cruise the "highways." J Natl Cancer Inst. 1994;86:1115-8.

4. Glowniak JV. Medical resources on the Internet. Ann Intern Med. 1995;123:123-31.

5. Leap of faith over the data tap. Lancet. 1995;345:1449-51. Editorial.

6. Goldwein JW, Benjamin I. Internet-based medical information: time to take charge. Ann Intern Med. 1995;123:152-3.

7. Reynolds TM. Popular medical information on Internet. Lancet. 1995;346:250. Letter.

8. Sharma P. Popular medical information on Internet. Lancet. 1995; 346:250. Letter.

9. Spooner SA. On-line resources for pediatricians. Arch Pediatr Adolesc Med. 1995;149:1160-8.

10. Kassirer JP, Angell M. The Internet and the Journal. N Engl J Med. 1995;332:1709-10.

11. Zeligher J. Internet news: patient handouts from the Internet. MD Comput. 1995; 12:338-59.

12. Chute CG, Crowson DL, Buntrock JD. Medical information retrieval and WWW browsers at Mayo. In: Proceedings of the Annual Symposium on Computer Applications in Medical Care; 1995: 903-7.

13. Hoke F. Struggle over online cancer service spurs larger medical ethics debate. Scientist. 1995;9:1,6.

14. Keoun B. Cancer patients find quackery on the Web. J Natl Cancer Inst. 1996;88:1263-5.

15. Silberg WM, Lundberg GD, Musacchio RA. Assessing, controlling and assuring the quality of medical information on the Internet: Caveat lector et viewor-Let the reader and viewer beware. JAMA. 1997;277:244-5.

16. Gerr F, Letz R, Landrigan PJ. Upper-extremity musculoskeletal disorders of occupational origin. Annu Rev Public Health. 1991; 12:543-66.

17. Young JH. American Health Quackery. Princeton, NJ: Princeton University Press; 1992.

18. Young JH. The paradise of quacks. NY State J Med. 1993;93:127-33.

19. Dehart OW. Quackery: the modern highwayman. South Med J. 1992;85:793-4. Editorial.

20. Sullivan-Fowler M. Doubtful theories, drastic therapies: autointoxication and faddism in the late nineteenth and early twentieth centuries. J Hist Med Allied Sci. 1995;50:364-90.

21. Dwyer J. Fertile field for fads and fraud. Questionable nutritional therapies. NY State J Med. 1993;93:105-8.

22. Macklis RM. Magnetic healing, quackery, and the debate about the health effects of electromagnetic fields. Ann Intern Med. 1993; 118:376-83.

23. Strosberg JM. Reflections on the use of unproven arthritis remedies. NY State J Med. 1993;93:118-9.

24. Jarvis WT. Allergy-related quackery. NY State J Med. 1993;93: $100-4$.

25. Lerner IJ. Cancer quackery. Psychiatric Med. 1987;5:419-29.

26. Sampson WI. AIDS fraud, finances, and fringes. NY State J Med. 1993;93:92-6.

27. Unproven methods of cancer management: Laetrile. CA Cancer $\mathrm{J}$ Clin. 1991;41:187-92.

28. Osterweis M. Bereavement intervention programs. In: Osterweis M, Solomon F, Green M, eds. Bereavement: Reactions, Consequences, and Care. Washington, DC: National Academy Press; 1984.

29. Reissman F, Carroll D. Self-help and the new health agenda. In: Redefining Self-Help Policy and Practice. San Francisco, Calif: Jossey-Bass Publishers; 1995.

30. Jacobs MK, Goodman G. Psychology and self-help groups: predictions on a partnership. Am Psychol. 1989;44:536-45. 